\title{
1. Unprecedented challenge: implications for climate resilient urban planning
}

Anja Wejs

\section{THE CLIMATIC CHANGES AND THEIR IMPACT ON URBAN PLANNING}

Reckien et al. $(2018,2019)$ provide an extensive overview of the global status of CC (climate change) planning and find that less policy activity is taking place in adaptation as compared with mitigation, and that $\mathrm{CC}$ adaptation (CCA) initiatives are at an early stage, however, with Northern Europe being a frontrunner. Salvia et al. (2021) analyse 327 European cities' climate mitigation plans and conclude that the current mitigation actions by cities are not ambitious enough to meet the Paris Agreement that aims to limit the global mean temperature rise this century to below $1.5^{\circ} \mathrm{C}$ above pre-industrial levels. To meet this target, European cities need to double their efforts.

Looking at the observed climatic changes, the observations currently follow the high-end scenario of the UN Intergovernmental Panel on Climate Change (IPCC), termed the RCP8.5 scenario. This scenario is the Business as Usual (BAU) scenario, meaning the expected rise in temperature if the GreenHouse Gas (GHG) emissions remain unchanged. The development of $\mathrm{CO}_{2}$ in the atmosphere provides no indication of bending the curve, measurements by NOAA show an increase from below 380 parts per million (ppm) of $\mathrm{CO}_{2}$ in 2005 to above $410 \mathrm{ppm}$ in 2020 (NASA, 2020). To return to the levels of pre-industrial times, Bill McKibben and his 350.org campaign argues for a reduction of $\mathrm{CO}_{2}$ levels in the atmosphere to $350 \mathrm{ppm}$.

Following the RCP8.5 scenario we are to expect an increase of global mean surface temperature to $4.8^{\circ} \mathrm{C}$ by the end of the 21 st century (2081-2100) relative to 1986-2005. Temperature increase alone will cause sea level to rise between 0.45 to $0.82 \mathrm{~m}$ for the RCP8.5. scenario, whereas the contribution of melting ice from Antarctica and Greenland is not fully understood (IPCC, 2014). The sea level does not rise evenly across the globe due to regional changes in the gravitational field and land uplift. Grindsted et al. (2015) find that there is more than a $25 \%$ chance that the 0.82 metre figure is surpassed in 
Northern Europe, and a sea level rise up to $1.80 \mathrm{~m}$ is possible. On top of sea level rise comes increased storm surges due to higher ocean temperatures. CC further increases extreme weather events, such as heat waves, droughts, flash floods, landslides and hurricanes.

CC scenarios are very important in urban planning and development, as infrastructure and urban areas are laid out for the next 30 years or longer. It is therefore important to incorporate $\mathrm{CC}$ in the design of urban planning to avoid construction in flood-prone areas, to mitigate areas that will be flood prone in the future, and to design flood paths and cooling of the city. It is, furthermore, important to perform an integrated urban planning that incorporates all impact sources, that is, rising levels of the terrain-near groundwater (flooding from below), rising water levels from lakes and rivers (inland flooding), rising sea levels and increased storm surges (coastal flooding), increasing precipitation and flash floods (flooding from above), and combined events. A combined event can be, for example, a longer period with everyday precipitation causing increases in water levels of rivers, combined with a storm surge event that, together with the already high water levels, may cause a high-impact flood. In addition, accommodating increased drought and heat waves are to be integrated into the urban and spatial planning.

Therefore, each urban plan should as a minimum be based on a flood risk assessment accompanied with a set of mitigating actions (e.g., by an action plan). As simple as it seems, as difficult it is in practice! Water runs across any borders; physical as well as administrative, and CCA demands cross-sectoral and interdisciplinary collaboration.

\section{IMPLICATIONS FOR CLIMATE CHANGE PLANNING}

Cities all over the world are acting on $\mathrm{CC}$, as is well illustrated in the Assessment Reports on Climate Change and Cities (the ARC3-series) of the Urban Climate Change Research Network (UCCRN). It provides examples and inspiration for policymakers around the world on how cities act on CC, however, that does not mean that all cities act, or that every city succeeds.

Many of the experienced implications for $\mathrm{CC}$ in current urban planning are related to the climate scenarios and the cross-sectoral and interdisciplinary nature of CCA planning. Having a CC plan is not enough, CCA is to be integrated and mainstreamed into more or less all sectors of local government, and action is dependent on political prioritization and support. In the following, 10 implications for CC planning are discussed and examples are provided for inspiration to accommodate these implications. 


\section{Urbanization and Ongoing Urban Development}

Historically, cities have developed from the old city centre and outwards, and in relation to flooding, you can often put the history of the urban development into other words - from the high (dry) parts towards the low (wet) parts, meaning that the current urban development is often constructed in low flood-prone areas. You would think that a flood risk map or just paying attention to the area names (i.e., meadow, spring, swamp, lake, valley etc.) would ring a bell and make a planner think that this area might not be fit for urban development or at least it would need adaptation measures. However, urban development can be a complicated process where powerful entrepreneurs and land prizes are weighed higher than mitigation of future flood risks. In the cities, densification provides maximum profit for the developer, however, it leaves very little space, if any, for managing water, whereas the water runoff may cause flooding. Or it may be as simple as the professional backgrounds of the related planners are not related to water.

In some parts of the world, urbanization may also cause informal settlements, which due to the location and unstable constructions, these communities are specifically vulnerable in case of a flood or heat wave. Quarry Road West, an informal settlement in Durban, South Africa, is an example of the role of urbanization on settlements in low lying areas (Williams et al., 2018). Quarry Road West lies along a riverbank and in 2019 a flood removed 240 homes. CC puts stresses on areas already in jeopardy. The UN Environment Programme initiative Global Adaptation Network (GAN) supports the Educational Partnerships for Innovation in Communities (the EPIC Network) in, for example, Africa and Asia on disaster risk management planning, an initiative that supports local governments in building community resilience.

\section{Insufficient Data for Risk Mapping and Assessments}

There is great variety among countries and cities around the world on the access to and quality of available data and thus the basis for making precise flood risk assessments. In addition, access to knowledge on integration of CCA into urban planning also varies, which is important when the results of flood risk assessments are transferred into urban planning. The lack of accessibility and quality of data hampers the implementation of CCA. New technologies such as drones with remote sensing, satellite data and larger computing power may be the future for more detailed mapping. And more importantly, these technologies are to be accompanied with capacity building of the planners to understand the data and translate it into practice.

Another discussion point is, however, how precise data and modelling do we actually need to carry out good planning? In the case of Vinh Yen, a suburb 
of Hanoi, Vietnam, areas of the city experience flooding that also causes overflows from the sewer system. Instead of detailed hydraulic modelling, a qualitative risk-mapping was carried out with local stormwater and urban planners that identified the often-flooded areas, overflow points from the sewer and possible flow paths. This was supplemented by an estimation of expected precipitation in a given situation today and also under a future climate, which was compared with the capacity of the sewer system. The future urban expansion that was expected to be connected to the existing sewer system (already facing limited capacity) was taken into consideration. In this way, a relatively simple analysis provided an overview of the interlinkages between the flood risk areas, the sewer system, and urban development at present and in the future with the purpose to increase climate resilience. Another qualitative method for data collection is citizen science and to engage citizens in flood risk mapping based on their experiences from their every day stay in the area. These data may also supplement the quantitative data.

\section{Insecurity of Climate Scenarios}

Very few national governments have announced which climate scenario, such as the RCP8.5, the local authorities should apply in their planning. It is left to the local authorities to decide. The climate scenario will not only indicate what and when an area will be at risk of flooding, it also affects the type, size and price of adaptation measures. This lack of national commitment affects local motivation especially among the smaller cities. A country that has very clear standards is the Netherlands. About one-third of the country lies below sea level and with the lowest point being almost $7 \mathrm{~m}$ ( 22 feet) below sea level. The Netherlands is protected by a comprehensive water management system of dikes, dams, drainage and channels and it has a national standard for safety levels corresponding to an event statistically occurring once in 10,000 years. The authorities use several scenarios as a basis for flood protection and contingency planning, and for their CCA strategy, and they operate with "worst case floods". The main reason for this strategy is that the Netherlands cannot afford not to, as the direct and indirect damage costs are too high. Solutions that may not demand detailed insights into scenarios are nature-based solutions (NBS), for example, by building coastal protection with mangroves such as the "Building with Nature" project on the Northern coast of Java, Indonesia.

\section{Incoherence between the City and its Surroundings}

Urban CCA have, to a wide extent, focused on urban measures for water management of increased precipitation, flash floods and heat waves and with very little attention to the role of the surrounding countryside. Traditionally, cities 
have been founded near waterways, such as rivers, as they were the primary trade routes. The city has since expanded, leaving less land for the river in times of heavy precipitation. Tokyo, Japan, has implemented the largest flood storage in the world. It mitigates overflowing of the city's major waterways and rivers during rain and typhoon season, and it consists of five concrete containment silos with heights of $65 \mathrm{~m}$, diameters of $32 \mathrm{~m}$ and connected by $6.4 \mathrm{~km}$ of tunnels, $50 \mathrm{~m}$ beneath the surface. The cost was US\$2.6bn. The construction is impressive, however, expensive, and thus not applicable for all cities. Another solution is to delay and restore water upstream of a city by implementing NBS such as wetlands, waterholes, lakes and watercourse re-meandering, which also benefits ecosystems and biodiversity. Solutions in the hinterland are, nevertheless, not always straightforward. Landowners might not support the initiative and structural schemes may hamper the process. In the European Union (EU), the Common Agricultural Policy subsidises farmland. If a farmer decides to give up farming in, for example, low-lying peatland for the benefit of the climate, the farmer loses parts of the subsidy. This is despite the fact that the lowland would not make profit without the subsidy and that taking the land out of production benefits storage of GHG emissions from peatland and protects downstream urban areas from flooding by retaining water. Implementation of CCA projects in the hinterlands may, for structural reasons, take many years.

\section{Sector Oriented Action}

$\mathrm{CC}$ affects most sectors related to urban planning: stormwater management, zoning plans, infrastructure, the built environment, contingency planning, health, and so on, and CCA planning demands for coordination and collaboration across the sectoral silos, and between local governments and other actors such as utility companies, private landowners and citizens. Though cities are frontrunners in CCA planning, it is also well documented in the scientific literature that the existence of a variety of practical barriers to developing coordinated and cross-sectoral plans and securing their subsequent implementation is hampering action. Local governments have traditionally not been accustomed to work across silos, and it is a new practice which in these years is being formed. CCA being a new practice in an institutional void with weak division of responsibilities among the relevant actors, constitutes the risk that CCA falls between two (or more) stools. Instead of focusing on responsibility lines, there is a need for cities to take a problem-based approach on the issue at stake, gather the relevant stakeholders and build the process from there. The cities that seem to succeed are those that possess a policy entrepreneur that brings the agenda forward and/or where the city applies the climate agenda for local development and branding (Wejs, 2013). 


\section{Lack of Coordination between Neighbouring Municipalities}

When neighbouring municipalities apply different scenarios and/or different background information for modelling, it is difficult to compare cross-municipal impacts and coordinate CCA in a joint effort. The coordination becomes even more difficult if the regional authority does not have or take the coordinating role. In this case conflicts can arise between neighbouring municipalities when, for example, flooding is not managed, or drought causes lack of water in the rivers. In the EU LIFE project Coast to Coast Climate Challenge (C2C $\mathrm{CC}$ ) a sub-project deals with collaboration between seven municipalities in Denmark on the creation of a shared hydraulic model of a large water catchment area of the River Gudenaa. Besides the hydraulic model, a damage costs analysis and an added value assessment provide a common basis for future CCA along the total river system. The aim of the project is to manage the water and avoid flooding of prioritized values and the cities along the river.

\section{Priority is Given to Short Term Policy Topics}

A very well-known dilemma in CC planning is the shifting political priorities of a city. The city government consists of politicians elected for a short period of time, and where re-election is an underlying main driver. Therefore, short-term policy areas are often prioritized over long-term areas such as providing the resources to plan ahead and integrate CCA into ongoing urban development and infrastructure to protect the city in the future. What might be an added cost now, is cheaper in the long run, for example by implementing a new sewer system in 10 years instead of laying down a bigger pipe size today. To convince decision makers it can aid the implementation process to draw on other policy areas as catalysts for CCA, in Vinh Yen, Vietnam, the local government and the Vietnam Institute for Urban and Rural Planning (VIUP) joined forces in exploring the synergies between CCA and urban farming. At that point in time, there was a growing awareness among the population on organic and safe products and many middle-income families grew their own crops on balconies, on rooftops and in back yards. A joint pilot project funded by the Nordic Development Fund (NDF) explored the feasibility of rainwater harvesting with urban farming and the CCA effect of a low budget CCA initiative mainly driven by citizens. A CCA solution with many synergies to the UN Sustainable Development Goals (SDGs) (Öhlander et al., 2019).

\section{The Smaller Cities Lag Behind}

As early as in 2010, Cynthia Rosenzweig published an article in Nature with the title "Cities Lead the Way in Climate-Change Action" (Rosenzweig et al., 
2010). The C40s network has taken a lead role as a forum between the largest and most prominent cities globally to discuss and inspire on climate action. However, these cities are also the elite, and Salvia et al. (2021) find that the smaller cities need the support of higher levels of government and other stakeholders. In addition, the city level is too small in scale to deal with $\mathrm{CC}$, and several municipalities must work inter-municipally and regionally to meet the limitations of working within the municipal boundaries. The inter-municipal work can help to solve it, but also create inertia or conflict in the process. The $\mathrm{C} 2 \mathrm{C} \mathrm{CC}$ project, mentioned above, is an example of an inter-municipal collaboration where middle sized and smaller cities work together in joint CCA projects. It is managed by a regional authority which works as moderator and facilitator for knowledge sharing and capacity building, and the project further has a networking role for the municipal officials involved. In addition, Wejs (2013) finds that small cities in Denmark move on the CC agenda, when it is combined with local development strategies, that is, creation of jobs within the wind and renewable energy sector or business development within the water technology sector. Finding a local narrative already on the agenda may be a strategy to create legitimacy for local climate action.

\section{Extreme Weather Events as CCA Drivers}

The annual cost of adaptation in the EU is estimated at $€ 1.5$ billion/year by the 2050s. Without CCA, the estimated costs of recovery and compensation will be six times as high. Though socio-economic analyses often show that precautionary measures are of lower costs than the damage costs, it is not unusual that action follows the wake of an extreme event. For that reason, you can also term an extreme weather event a "granting event", as it increases the sense of urgency and makes the politicians free resources for CCA. Hurricane Sandy, that hit New York City in 2012, was also named Superstorm Sandy and it brought CC to the political agenda as contributing with several warming-related factors that intensified the impact of the storm. Sandy resulted in 44 deaths and inflicted an estimated US\$19 bn in damages and lost economic activity. Hurricane Sandy was the "tipping point"' leading to transformative adaptation due to the explicit inclusion of increasing CC risks in the rebuilding effort (Rosenzweig and Solecki, 2014). Another example is the heat wave over Europe in 2003 that caused a significant number of deaths, including 500 residents in Paris. This resulted in a national heat emergency plan in France, and Paris has implemented cool rooms, pools and water fountains as heat emergency responses. One can imagine that Augmented Reality (AR) in the coming years may be a CCA tool for decision making to be at the forefront of the impacts of extreme weather events. 


\section{Synergies and Trade-Offs between Climate Mitigation and Adaptation}

Though CC plans often include both climate mitigation and adaptation (Reckien et al., 2018), the two strands are in practice carried out separately. Mitigation dealing with reducing carbon emission within the sectors related to energy production, energy consumption, buildings, and transportation. CCA dealing with adaptation to either more or less water and more extreme weather events. When talking about urban planning, there are obvious synergies, however, also trade-offs between mitigation, adaptation and other environmental concerns. Examples of trade-offs are urban densification to reduce $\mathrm{CO}_{2}$ emissions which may increase the urban heat island effect and precipitation runoff. Examples of synergies are urban green spaces to store precipitation runoff and which also contribute to cooling the city, increase urban biodiversity, function as carbon sinks and improve air quality (Wejs, 2014). Working strategically with green spaces in the city and with synergies will increase the quality of the climate actions.

These 10 implications are examples of planning mechanisms often creating inertia in the pace of CCA implementation in practice. The mechanisms are many-fold and context-dependent but how these implications are dealt with in practice is pivotal for the preparedness of a city to accommodate the future climate impacts.

\section{LIKELY SCENARIOS FOR FUTURE URBAN PLANNING}

Bostrom (2002) defines CC as an existential risk; a risk where humankind as a whole is imperilled, and that our societies are not geared to manage $\mathrm{CC}$ as the scale of the risks is simply too difficult to grasp. Around the world, this difficulty can be observed in the political reality. Not only in terms of the impact of climate deniers on the political agendas, but also in countries recognizing CC as a threat for modern society, the societal transition is not supported by political action. Greta Thunberg arrived on the political scene at a moment where the majority recognized the magnitude of the consequences of $\mathrm{CC}$, and she managed to create a movement building on science carried forward by climate scientists and the UN's Intergovernmental Panel on Climate Change (IPCC). Even though the impression is that many politicians want to do more, action is missing on the political agenda. In many countries voters support climate action, but the political analysis is perhaps also that the support of the voters only lasts as long it does not "hurt".

Within the arguments of Greta Thunberg lies the role of equity between generations. This argument of equity was a result of the UN report "Our Common 
Future", also named The Brundtland Report, published in 1987 (UN, 1987). It defined sustainable development as a term on the global political agenda with its definition: "development that meets the needs of the present without compromising the ability of future generations to meet their own needs". This definition involves three dimensions of sustainability: an economic, an environmental and a social. It was a widespread belief that considerations for future generations could be combined with economic growth. In the post-Brundtland period, focus has been on cleaner technology with the aim to increase sustainability without limiting growth. This assumption can be regarded in the light of the I=PCT formula from the 1960s and 1970s debate on environmental degradation, global population growth and over extraction of the Earth's resources (Arler et al., 2015). This formula grasps the overarching components of environmental impact, where (I) = Environmental Impact, $\mathrm{P}=$ Population, $\mathrm{C}=$ Consumption and $\mathrm{T}=\mathrm{Technology}$. As the increase in global population is difficult to manage, focus on the post-Brundtland period was to a wide extent on technological development.

The present debate on ways to solve the climate crisis can roughly be divided in two, a debate related to degrowth and reduced consumption with the aim to reduce $\mathrm{CO}_{2}$ emissions (related to $\mathrm{C}$ in the $\mathrm{I}=\mathrm{PCT}$ formula), and a debate related to technological development and an optimism in technology to save modern society (related to $\mathrm{T}$ in the $\mathrm{I}=\mathrm{PCT}$ formula). A popular read on CC is Wallace-Wells' The Uninhabitable Earth (2019) where the physical climatic changes and its impacts are explained for laymen. The book serves as an example of the I=PCT debate, where the chapter titles "Crisis Capitalism", "The Church of Technology" and "Politics of Consumptions" are examples of the discussions between reduced consumption and degrowth (C), and technological optimism (T) and the underlying issue with global population growth (P) that together with climate impacts can lead to, not only natural disasters, but also food crisis and migrations.

The I=PCT formula is also an underlying topic in another popular read by Quartz, the futuristic article "Welcome to Leeside, the first US's climate haven" (Shendruk, 2020) spins on a city that applies the climate crisis as an opportunity for development by creating a climate resilient city - in which it in many ways succeeds. Looking at the future for urban planning, the story of Leeside presents an urban development that incorporates CCA making it feasible and attractive to live in a future climate. Societies that, as Leeside, illustrate how the future urban planning might look like are provided in the following three examples. A present society that is at the forefront of CCA is the Netherlands, whose very existence depends on their flood protection and management through a traditional engineering approach with hard measures such as concrete canals, drainage pipes and dikes. Up to $1 \%$ of BNP can annually be spent on flood protection and the costs per household is less 
than 2 euros per day which is paid over water taxes. A smaller city that, as Leeside, picked up the climate agenda as an urban development opportunity is Randers, Denmark. Randers is a high flood risk area appointed under the European Floods Directive, located in a delta area at the entrance of the largest Danish water course. It is further an old industrial town with a relatively bad reputation, which the city would like to change. Based on a flood risk management plan, an urban master plan is developed with the vision "The City Towards the Water", illustrating the urban transition from an industrial town with heavy industry at the waterside to a town that applies NBS and CCA to create an attractive city. A third example, related to drought and heat waves, is Abu Dhabi, located in the desert, where the climate is extremely hot and low in precipitation; the country's very large energy consumption is used, for example, for air conditioning and fresh water supply, the latter produced via desalination of seawater. All three examples show that the challenges for urban development are not technical. Nor was it the technical solutions and the urban development which prevailed in the story of Leeside.

Leeside succeeded with its urban development as a means for branding the city and attracting citizens. However, in the end the society of Leeside is stressed due to rising property prices and an overwhelming number of migrants. The story of Leeside can also be regarded as an analogy to the European refugee and migrant crisis that peaked in 2018. The refugee and migrant crisis were linked to $\mathrm{CC}$, as prior to the Arab Spring, there was a historically severe drought in Syria that forced people from country to city, thus creating pressure on society and intensifying the conflict. The story of Leeside also provides an example that the climate crisis is not only solved at city-level, but it also demands intercity, interregional and international action. That is not an easy fix. The COVID-19 crisis, however, has taught us that we live in a fragile world and that rapid decision-making at all tiers of government, is possible. It has also taught us that there is no shortage of money to support the existing economy. There is thus an opportunity in the post-COVID-19 period to define a new normal for a low carbon and resilient economy enabling clever investments in CCA.

\section{ACKNOWLEDGEMENT}

The time for writing this chapter is funded by the EU LIFE IP project Coast to Coast Climate Challenge (C2C CC) and Central Denmark Region. 


\section{REFERENCES}

Arler, F., Mosgaard, M. A. and Riisgaard, H. (2015). Chapter 1 and 3 in Baredygtighed: Vcerdier, Regler og Metoder. Arler, Mosgaard and Riisgaard (eds), Aarhus Universitetsforlag.

Bostrom, N. (2002). Existential risks: analyzing human extinction scenarios and related hazards. Journal of Evolution and Technology, 9(1), 1-30.

Grindsted, A, Jevrejeva, S., Riva, R. E. M. and Dahl-Jensen, D. (2015). Sea level rise projections for northern Europe under RCP8.5. Climate Research, 64(1).

IPCC (2014). Climate Change 2014: Synthesis Report. Contribution of Working Groups I, II and III to the Fifth Assessment Report of the Intergovernmental Panel on Climate Change [Core Writing Team, R.K. Pachauri and L.A. Meyer (eds)]. IPCC, Geneva, Switzerland, $151 \mathrm{pp}$.

NASA (2020). Vital signs of the planet. https://climate.nasa.gov/vital-signs/carbon -dioxide/ (accessed 25 November 2020).

Öhlander, E., Pedersen, M., Wejs, A., Bonde, M. A. S. and Lehmann, M. (2019). Guidance on integrating the SDGs in urban climate change adaptation projects. NIRAS and Aalborg University.

Reckien, D., Salvia, M., Heidrich, O., Church, J. M. ... Dawson, R. (2018). How are cities planning to respond to climate change? Assessment of local climate plans from 885 cities in the EU-28. Journal of Cleaner Production, 191, 207-219.

Reckien, D., Salvia, M., Pietrapertosa, F., Simoes, S. G. ... Heidrich, O. (2019). Dedicated versus mainstreaming approaches in local climate plans in Europe. Renewable and Sustainable Energy Reviews, 112, 948-959.

Rosenzweig, C., Solecki, W., Hammer, S. and Mehrotra, S. (2010). Cities lead the way in climate-change action. Nature, 467, 909-911. https://doi.org/10.1038/467909a.

Rosenzweig, C. and Solecki, W. (2014). Hurricane Sandy and adaptation pathways in New York: Lessons from a first-responder city. Global Environmental Change, 28, 395-408.

Salvia, M., Reckien, D., Pietrapertosa, F., Eckersley, P. ... Heidrich, O. (2021). Will climate mitigation ambitions lead to carbon neutrality? An analysis of the local-level plans of 327 cities in the EU. Renewable and Sustainable Energy Reviews, 135.

Shendruk, A. (2020). Welcome to Leeside, the US's first climate haven. Quartz. https://qz.com/1891446/welcome-to-leeside-the-uss-first-climate-haven/ (accessed 25 November 2020).

UN Secretary-General, World Commission on Environment and Development. (UN) (1987). Report of the World Commission on Environment and Development: 'Our common future' [Brundtland report]. file://Users/anjawejslarsen/Downloads/ A_42_427-EN.pdf.

Wallace-Wells, D. (2019). The Uninhabitable Earth - A Story of the Future. Guardian.

Wejs, A. (2013). Climate for change? Integrating climate change into cities' planning practices. PhD Thesis. Aalborg University.

Wejs, A. (2014). Integrating climate change into governance at the municipal scale: an institutional perspective on practices in Denmark. Environment and Planning, $C$ 32(6), 1017-1035.

Williams, D. S., Costa, M. M., Celliers, L. and Sutherland, C. (2018). Informal settlements and flooding: identifying strengths and weaknesses in local governance for water management. Water, 10(7), 871 . 